\title{
PARALISIA PERIODICA TIREOTOXICA
}

\author{
REGISTRO DE UM CASO \\ ATHOS SCHERER TORRES * \\ ALBERTO DIETRICH *** \\ GUALBERTO R. M. MEDINA ** \\ MARIO F'. COUTINHO **** \\ ODILON DUTRA DOS SANTOS **
}

Nas doenças com debilidade muscular episódica o paciente tem contrações musculares normais nos períodos intercríticos. Os surtos de debilidade variam desde uma discreta paresia até uma verdadeira plegia, ocorrendo recuperação da força muscular em pequeno espaço de tempo 10,14,16,20,25.

As doenças com debilidade muscular temporária podem ser agrupadas da seguinte maneira, segundo Swaiman \& Wright 25: 1 - Com alteração na concentração sérica de potássio: a) Paralisia periódica clássica (paralisia periódica familiar hipopotassêmica e paralisia periódica familiar hiperpotassêmica); b) Aldosteronismo; c) Tireotoxicose com debilidade episódica; d) Nefropatia com perda de potássio. 2 - Sem alteração na concentração sérica de potássio: a) Paramiotonia congênita; $b$ ) Doença de McCardle; c) Miopatia mitocondrial do tipo pleoconial (paralisia periódica familiar normopotassêmica). Podemos ainda lembrar outras entidades em que a debilidade episódica é encontrada: 1 - Mioglobinúria familiar paroxística (doença de Meyer-Betz); 2 - Polimiopatia alcoólica; 3 - Miopatia cortisônica; 4 - Adinamia episódica hereditária (Doença de Gamstorp); 5 - Porfiria intermitente aguda hereditária.

A paralisia periódica tireotóxica foi descrita pela primeira vez em 1926 por Shinosaki, citado por Albeaux-Fernet ${ }^{1}$; a partir desta data surgiu um grande número de publicações japonesas relacionadas à associação de hipertiroidismo com debilidade muscular episódica. Entretanto, a literatura européia é escassa em publicações deste gênero, sendo que o primeiro relato de paralisia periódica com hipertiroidismo publicado na Grã-Bretanha ocorreu em $1975^{2}$. Em nosso meio acreditamos ser esta a primeira publicação referente ao assunto.

Geralmente os ataques de paresia ou plegia surgem logo que começam as manifestações clínicas de tireotoxicose. No entanto, há casos em que a debilidade muscular ocorre antes de qualquer sinal clínico de disfunção tiróidea, podendo também ter início simultâneo ${ }^{8,25}$. Habitualmente a doença tem 0 seu início na idade adulta; entretanto, existem relatos de casos em que a debilidade muscular manifestou-se antes dos 19 anos de idade 8,9 . E unânime a afirmativa

Trabalho do Serviço de Neurologia e Neurocirurgia Dr. Mario Coutinho, Hospital Beneficencia Portuguesa (Porto Alegre); "Chefe de Clínica; ** Médicos Residentes; ***Endocrinologista ****Chefe do Serviço. 
de que há nítido predomínio do sexo masculino sobre $o$ feminino de até $6: 12,3,4,8,9,10,11,12,15,16,17,18,25$. A incidência da doença nas pessoas de raça amarela com hipertiroidismo está em torno de 2-8\% 15,16,17,18 e se considerarmos unicamente os adultos hipertiroideos de raça amarela a incidência pode chegar até 33\% 18. McFadzean ${ }^{15}$ salienta que a debilidade muscular episódica é uma complcação do hipertiroidismo tão frequente nos chineses quanto nos japoneses. Seria então um defeito geneticamente determinado na raça amarela, cuja evidência clínica seria precipitada pela tireotoxicose. Este autor é o primeiro a referir-se a uma característica sasonal da paralisia periódica tireotóxica, como seja o fato de ocorrerem os ataques preferencialmente no verão.

A paralisia periódica tireotóxica simula clinicamente uma paralisia periódica familiar hipopotassêmica e embora também se acompanhe de hipopotassemia, não há história familiar da doença. Ambas entidades nosológicas se apresentam como ataques de paralisia flácida que comprometem principalmente a musculatura extensora dos membros e do tronco poupando, na maioria dos casos, exceto nos gravíssimos, a musculatura facial, respiratória e faríngea. Pode acompanhar-se de hipo ou arreflexia tendinosa. Os ataques podem assemelhar-se a crises de neurose conversiva ${ }^{14,20}$. Alguns fatores podem desencadear a crise como o exercício físico extenuante seguido de repouso imediato; ingestão excessiva de carbohidratos, administração de insulina ou adrenalina ?. Estudos recentes demonstram que pode haver uma relação direta entre o estado hiperadrenérgico do paciente hipertiroideo e a paralisia periódica. Verificou-se que após o uso de beta-bloqueadores desaparecem ou diminuem de intensidade os surtos de paralisia provocados por droga (insulina, adrenalina, glicose) ${ }^{5,21,26}$. Shishiba e col..23 demonstraram alteração na insulina endógena durante os ataques espontâneos de paralisia periódica tireotóxica. Estes autores acreditam que haveria uma reação anormal da permeabilidade da membrana muscular à sobrecarga de insulina, ocorrendo, em resposta, despolarização contínua e debilidade muscular.

\section{OBSERVAÇAOO}

A. P., 20 anos, sexo masculino, branco, brasileiro, internado em 01-08-75 (Registro no 5710). O paciente apresentava, como queixas principais, vómitos e impossibilidade de movimentar os membros inferiores episodicamente. Há aproximadamente 7 meses teve episódio de falta de força nos membros inferiores, após refeiçăo abundante; a paralisia durou aproximadamente 30 minutos. Não apresentou qualquer outro sintoma na ocasiáo. Há 4 meses, de madrugada, teve novo episódio de falta de forças nos membros inferiores. Percebeu este sintoma a tentar virar-se no leito, persistindo esta dificuldade aproximadamente 4 horas. $O$ exame neurológico mostrou paraparesia crural, sendo que o restante do exame năo mostrou anormalidades. 0 exame clínico geral mostrou frequência ventricular de 104 batimentos por minuto e o restante do exame clínico tampouco mostrou alteraçōes. Năo havia história familiar de quadro semelhante e o paciente não vinha fazendo uso de qualquer medicação. Após 4 horas o paciente estava assintomático. Atribuido o episódio a fatores psicológicos, o paciente foi encaminhado para tratamento psiquiátrico. Uma semana antes da hospitalização apresentou três episódios, de madrugada, de debilidade motora semelhantes aos anteriores. No 
último episódio referia dificuldade para movimentar os 4 membros, principalmente os inferiores. Năo referia dificuldade para respirar e mantinha controle esfincteriano. Apresentou vômitos durante a noite. Quatro horas após estava assintomático sem o uso de qualquer medicação. O paciente foi internado logo depois do último episódio de paralísia. Antecedentes obstétricos e gestacionais sem particularidades. Passado cirúrgico: amigdalectomia há longo tempo.

Exames neurológico - Paciente consciente, coerente, orientado auto e alopsiquicamente. Tetraparesia de predomínio crural tanto da musculatura extensora quanto da flexora. Hipotonia generalizada. Hiporreflexia profunda, mais acentuada nos membros inferiores. Reflexo cutaneo-plantar em flexão bilateral. Não foram assinaladas fasciculaçð̃es nem presença do fenômeno miotônico. Sensibilidades táctil e dolorosa normais. Sensibilidades palestésica e artrognósia normais. Nenhum sinal de irritação meningogorradicular. Pupilas isocóricas e fotorreagentes. Fundo de olho normal. Exame do restante dos nervos cranianos sem particularidades. Pesquisa da coordenação e equilibrio prejudicados. Exame clínico geral - Paciente longilíneo em bom estado geral, mucosas úmidas e coradas. Ganglios, pele e faneros sem particularidades. Pulsos periféricos todos palpáveis. Tecido celular subcutaneo, do pescoço, do tórax e do abdômen sem particularidades. Aparelho cardiovascular: ausculta cardiaca normal; frequencia ventricular 104 batimentos por minutos; pressão arterial 12x8 (ambos os membros superiores) pulmóes e aparelho gênito-urinário sem anormalidades.

Exames paraclinicos - Radiografias simples de coluna cervical, dorsal e lombusacra, normais. Radiografia do coração e vasos da base, normal. Eletrocardiograma: crescimento auricular esquerdo com transtorno da condução intraventricular e alteração na repolarização ventricular. Hemograma: 4.9 milhzes de hemácias/mm3; hemoglobina $14.4 \mathrm{~g} \%$; hematócrito 44\%; forma hemática normal; valor globular 1.02; 7.100 leucócitos/mm3, com suąs fraçóes dentro dos limites da normalidade. Velocidade de sedimentação globular normal. Creatinemia $2.5 \mathrm{mg} \%$; Magnesemia 1.2. $\mathrm{mEq} / 1$. Creatinina $0.8 \mathrm{mg} \%$. Uréia $26 \mathrm{mg} \%$. Sódio $138 \mathrm{mEq} / 1$. Potássio 3.8. $\mathrm{mEq} / 1$. Cloretos $108 \mathrm{mEq} / 1$. Reserva alcalina $26 \mathrm{mEq} / 1$. Creatina-fosfoquinase normal. Transaminases, valores normais. Punção lombar: pressão inicial $120 \mathrm{~mm}$ H20; pressão final $80 \mathrm{~mm}$ H20 com resposta normal d̀s provas raquemanométricas. Liquido cefalorraquidiano: 3 elementos $\mathrm{mm} 3,30 \mathrm{mg} \%$ proteinas, $70 \mathrm{mg} \%$ glicose, $730 \mathrm{mg} \%$ cloretos; Reaçбes globulínicas negativas: exames bacterioscópico e bacteriológico sem anormalidades; pesquisa de bacilos de Koch negativo; Reação de Weinberg negativo; Reaçðes de Wassermann e VDRL negativas; eletroforese das proteinas no liquido cefalorraquidiano: proteinas totais $30 \mathrm{mg} \%$; pré-albumina $4.0 \mathrm{mg} \%$; albumina $66 \mathrm{mg} \%$; alfa 1 globulina $3.0 \mathrm{mg} \%$; alfa 2 globulina $6.0 \mathrm{mg} \%$; beta globulina $9.0 \mathrm{mg} \%$, gamaglobulina $12.0 \mathrm{mg} \%$. Exame comum de urina normal. Volume urinário emitido em 24 horas $1.800 \mathrm{ml}$. Creatinúria $8 \mathrm{mg} / \mathrm{Kg} 24$ horas. Eletromiografia normal (após a crise). A investigação endocrinológica forneceu os seguintes dados: cabelos finos, oleosos; pele quente, amida, firme, tremor fino nas extremidades superiores; tremor da lingua que se mostra despapilada; bócio multinodular, moderado, móvel, indolor, elástico, sem sopro ou frêmito; olhar brilhante, não havendo exoftalmo. Metabolismo basal 32\%; Captação de T3 radioativo 73\%; T4 sérico $16 \mathrm{ug} / 100 \mathrm{ml}$; Indice T4 livre, 15; Fotomograma aquileu: $\mathrm{AD}-220, \mathrm{CD}-100, \mathrm{BD}-128$. 


\begin{abstract}
Evoluço - Foi instituldo tratamento para hipertiroldismo com propiltiouracil, 150 $\mathrm{mg} 8 / 8$ horas. O paciente teve alta em 06-08-75, assintomático, com a recomendação de manter controle ambulatorial neurológico e endocrínológico. Há três anos continua assintomático.
\end{abstract}

\title{
COMENTARIOS
}

Imediatamente após a internação do paciente ficou evidente que se tratava de um caso de paralisia periódica. Das paralisias periódicas que se acompanham de hipopotassemia afastou-se o aldosteronismo porque o paciente não apresentava cefaléia, hipertensão arterial sistêmica, polidipsia e poliúria. Os exames de laboratório não evidenciaram hipernatremia ou alcalose. Igualmente foi afastada a possibilidade de tratar-se de uma nefropatia expoliadora de sal ou pielonefrite crônica, pois não havia dados laboratoriais ou na história da doença que apoiassem esta cogitação. Para o diagnóstico diferencial lembramos a paramiotonia congênita, doença genética com herança autossômica dominante e que tem suas manifestações clínicas já na primeira infância; a debilidade muscular é mais evidente na cintura escapular e pélvica podendo, com a evolução da doença, manifestar-se sem o fenômeno miotônico. Alguns autores identificam a paramiotonia congênita com a paralisia periódica familiar hiperpotassêmica ou adinamia hereditária familiar (doença de Gamstorp) embora na paramiotonia o potássio sérico não sofra alteração $6,10,13,16$. Em nosso caso não havia antecedentes na infância e não havia fenômeno miotônico. Ainda nas entidades que provacam paralisia periódica com taxa de potássio sérico normal, lembramos a doença de McGardle que é devida à deficiência genética da miofosforilase, enzima que metaboliza a glicose ${ }^{6}$ - fosfato em ácido láctico e pirúvico; por isto, a dosagem de ácido láctico sérico imediatamente após exercício físico revela notável diminuição dos valores considerados normais ${ }^{\mathbf{1 0 , 2 2}}$. A doença é de caráter autossômico recessivo e se caracteriza clinicamente por má tolerância aos exercícios físicos, debilidade flácida episódica e câimbras durante esforços físicos. No caso relatado não havia sido assinalada intolerância aos exercícios físicos em qualquer fase da vida do paciente.

A porfiria intermitente aguda hereditária se deve a um erro do metabolismo de caráter genético autossômico dominante. Ocorre uma formação excessiva de porfobilinogênio e de seu precursor, ácido delta-amino-levulínico, decorrente de níveis hepáticos elevados da enzima ácido delta-amino-levulínico-sintetase (por isso também chamada de porfiria hepática aguda). São detectados niveis elevados de uroporfirina e coproporfirina, na urina e fezes, respectivamente. Doença de patogenia desconhecida, caracteriza-se por distúrbios no sistema nervoso central (distúrbios de conduta, convulsões), no sistema nervoso periférico (polineurites, com sinais de debilidade muscular episódica), dores abdominais em cólica, intensas. Alguns fármacos podem desencadear a crise, como barbitúricos e hidantoinatos. A menstruação também pode ser fator desencadeante. E doença rara antes da puberdade $\mathbf{1 0 , 1 6}$.

A miopatia mitoconrial do tipo pleoconial se caracteriza, aos estudos com microscópio eletrônico, por apresentar número elevado de mitocôndrias anômalas 
e de tamanho aumentado ${ }^{25}$. Clinicamente se caracteriza por flacidez já ao nascer e surtos de debilidade flácida que duram mais do que 10 dias. A atividade sérica enzimática é normal e também a taxa de eletrólitos. O eletromiograma se apresenta dentro dos padrões de doença miopática. A miopatia cortisônica apresenta surtos de debilidade episódica que comprometem a musculatura proximal e a cintura pélvica, preferencialmente. Não há correlação entre dose, tempo de corticoterapia e paralisia. A polimiopatia alcoólica ocorre após uso abusivo de bebidas alcoólicas e está associada a miocardiopatia alcoólica; há sinais de insuficiência cardíaca congestiva, intensa mionecrose com altos níveis séricos de transaminases e, também, mioglobinúria. Acredita-se que se deva a deficiência transitória de miofosforilase ${ }^{10}$. A mioglobinúria familiar paroxística (doença de Meyer-Betz) se caracteriza clinicamente por surtos de debilidade episódica por ocasião das crises de mioglobinúria, que podem ser desencadeadas por infecções ou por exercício físico intenso; há rigidez, edema e dor muscular; pode haver apenas uma crise ou ser recurrente. Conjectura-se que seja devida a defeito enzimático com redução da tolerância da miofibrila a atividade máxima (falha do metabolismo anaeróbio)10,16,25.

A paralisia periódica familiar hipopotassêmica é herdada em caráter autossômico dominante, predominantemente pelo sexo masculino. Os surtos ocorrem mais à noite, ou pela manhã, após exercício físico violento ou ingestão abundante de alimentos ricos em glicídios. O primeiro episódio ocorre geralmente na segunda década $e$, com o decorrer da idade, o número de ataques tende a diminuir e até desaparecer. A paralisia dura em média 6-12 horas, é de predomínio crural e pode atingir os quatro membros. Há abolição dos reflexos tendinosos. $O$ ataque pode ser desencadeado pela administração de glicose, insulina, adrenalina e até gorduras. O exame laboratorial revela hipopotassemia, geralmente em torno de $2-3 \mathrm{mEq} / 1$. O eletrocardiograma mostra bradicardia e inversão da onda $T$. A eletromiografia revela padrão de interferência com redução progressiva do número de unidades motoras que possam ser ativadas, duração reduzida dos potenciais de ação. Potencial de repouso normal e velocidade de condução dos nervos motores também normal. O tratamento da paralisia periódica hipopotassêmica é feito pela administração diária de potássio, com contrôle eletrocardiográfico e laboratorial. Também pode ser usada acetazolamida e espirolactona 10,14.16,19,20.

A paralisia periódica hiperpotassêmica ou adinamia episódica de Gamstorp se caracteriza por aparecer com níveis séricos elevados de potássio, durante a crise. $O$ primeiro ataque geralmente ocorre na primeira década da vida. As crises são de menor duração (1-2 horas) e intensidade do que as crises de paralisias periódicas hipopotassêmicas, porém são mais frequentes e com maior aparecimento de fenômeno miotônico. A debilidade é mais acentuada na cintura escapular, coxas e panturrilhas. Inicialmente o eletrocardiograma revela ondas $\mathrm{T}$ altas e agudas. O potássio sérico está alto. $\mathrm{O}$ sódio, cloretos e cálcio, via de regra, estão normais, embora haja relatos de hipocalcemia em associação com paralisia periódica hiperpotassêmica. ${ }^{6}$ A eletromiografia revela aumento no número de potenciais espontâneos, bem como presença de potenciais miotônicos. A excitabilidade muscular ao estímulo mecânico está muito aumentada. 
A velocidade de condução nervosa é normal. A microscopia eletrônica revela alterações mitocondriais semelhantes as da paralisia periódica hipopotassêmica. A administração de gluconato de cálcio a $10 \%$ resolve a crise 25 .

Uma explicação adequada da fisiopatogenia das paralisias periódicas permanece restrita a observações individuais dos bioquímicos sobre a atividade enzimática no metabolismo dos carbohidratos, ou dos fisiologistas estudando os potenciais de membrana antes, durante, e após o ataque de paralisia, e ainda dos patologistas que com a microscopia eletrônica tentam traçar paralelos nas alterações estruturais encontradas nestas entidades nosológicas; não havendo ainda conclusão satisfatória no que diz respeito a este complexo problema. Entretanto, salientamos que com estudos por microscopia eletrônica os patologistas acreditam que nas paralisias periódicas hipo e hiperpotassemica a lesão primária seria a ruptura das miofibrilas e degeneração mitocondrial e estariam relacionadas diretamente ao número de crises ${ }^{13}$. Assim sendo, as paralisias periódicas com instalação de debilidade permanente seriam explicadas pela vacuolização e degeneração irreversíveis das miofibrilas ${ }^{19}$. Salientamos a importância do diagnóstico correto para o tratamento adequado e prevenção de novos surtos de paralisia periódica em determinados pacientes.

\section{RESUMO}

É relatado um caso de paralisia periódica tireotóxica. Os autores chamam a atenção para o fato de não haver registro de publicações semelhantes na literatura brasileira nos 10 últimos anos. São abordados diversos aspectos do diagnóstico diferencial com outros tipos de paralisia periódica.

\section{SUMMARY}

Thyrotoxic periodic paralysis: a case report.

A case of thyrotoxic periodic paralysis based on clinical grounds, laboratory data and therapeutic response as well is reported. The authors comment on the differential diagnosis with the most frequent types of periodic paralysis. The importance of a correct diagnosis and treatment as early as possible is stressed as to prevent further development of permanent paralysis due to irreversible degenerative myofibril changes as stated in literature.

\section{REFERENCIAS}

1. ALbEAUX-FERNET, M. - Myopathies et hyperthyroidie. Sem. Hop. Paris 28:1720, 1966.

2. ALI, K. - Hypokalemic periodic paralysis complicating thyrotoxicosis, British Med. J. 4:503, 1975.

3. AU, K. S. - Thyrotoxic periodic paralysis. Arch. Neurol. Chicago 26:543, 1972.

4. BRODY, I. A. \& DUDLEY, A. W. - Thyrotoxic hypokalemic periodic paralysis. Arch. Neurol. (Chicago) 21:1, 1969. 
5. CONWAY, M. J.; SEIBEL, J. A. \& EATON, P. - Thyrotoxicosis and periodic paralysis: improvement with beta adrenergic blockade. Ann. Intern. Med. 81:332, 1974.

6. DYKEN, M. I. \& TIMMONS, G. D. - Hiperkalemic periodic paralysis with hypocalcemic episode. Arch. Neurol. (Chicago) 9:76, 1963.

7. ENGEL, A. G.; LAMBERT, E. H.; ROSEVEAR, J. W. \& TAUXE, N. - Clinical and electromyographic studies in a patient with prymary hypokalemic periodic paralysis. Amer. J. Med. 38:626, 1965.

8. ENGEL, A. G. - Electron microscopic observation in thyrotoxic and corticosteroid induced myopathies. Mayo Clin. Pro. 41:785, 1966.

9. ENGEL, A. G. - Electron microscopic observations in primary hypokalemic and thyrotoxic periodic paralysis. Mayo Clin. Proc. 41:797, 1966.

10. HARRISON, T. H. - Harrison's Principles of Internal Medicine. Mcyraw-Hill Book Co. New York, 1970.

11. KUSAKABE, T.: YÓSHIDA, M. \& NISHIKAWA, M. - Thyrotoxic periodic paralysis: a peculiar case with unusual dystonic behavior and variable relations of paralysis to serum potassium levels. J. Clinic. Endocrinol. Metab. 43:730, 1976.

12. LENORMAND, M. W.; GRAVELEAU, J.; LAFONT, J. \& MORIN, M. - Les myopathies hyperthioidiennes: a propos de trois observations. Sem. Hôp. Paris 51:2031, 1975.

13. McDONALD, R. N.; REWCASTLE, N. B. \& HUMPHREY, J. G. - The myopathy of hyperkalemic periodic paralysis. Arch. Neurol. (Chicago) 19:274, 1968.

14. McCARDLE, B. - Familial periodic paralysis. British Med. Bull. 12:226, 1956.

15. McFADSEAN, A. J. S. \& YEAUNG, R. - Periodic paralysis complicating thyrotoxicosis in chinese. British Med. 1:451, 1967.

16. MERRIT, H. H. - A Textbook of Neurology. Lea \& Febiger, Philadelphia, 1973.

17. MURIE, N.; SIMON, M.; EDAN, R.; SABBURAUD, O. \& BOUREL, M. Hyperthioidie et paralisie périodique. Sem. Hôp. Paris 47:1069, 1971.

18. NORRIS, F. H.; PANNER, B. J. \& STORMONT, J. M. - Thyrotoxic periodic paralysis. Arch. Neurol. (Chicago) 19:88, 1968.

19. ODOR, D. L.; PATEL, A. N. \& PEARCE, L. A. - Familial hypokalemic periodic paralysis with permanent myopathy: a clinical and ultrastructural study. J. Neuropath. Exp. Neurol. 26:98, 1967.

20. PEARSON, C. M. - The periodic paralysis: differential features and pathological observations in permanent myopathic weakness. Brain 87:341, 1964.

21. PIMSTONE, N.; MARINE, N. \& PIMSTONE, B. - Beta-adrenergic blockade in thyrotoxic myopathy. Lancet $2: 1219,1968$.

22. ROWLAND, L. P.; FAH. S. \& SCHOTLAND, D. L. - McCardle's disease. Arch. Neurol. (Chicago) $9: 13,1963$.

23. SHISHIBA, Y.; SHIMIZU, T.; SAITO, T. \& SHIZUME, K. - Elevated immunoreactive insulin concentration during spontaneous attacks in thyrotoxic periodic paralysis. Metabolism. 21:285, 1972.

24. SHIZUME, K.; SHISHIBA, Y.; SKUMA, M.; YAMAUCHI, H.; NAKO, K. \& OKINARA, S. - Studies on electrolyte metabolism and idiopathic and thyrotoxic periodic paralysis. Metabolism 15:138, 1966.

25. SWAIMAN, K. F. \& WRIGHT, F. S. - Enfermedades Neuromusculares en el Lactante y el Niño. Versão castelhana. Editorial Pediátrica, Barcelona, 1972.

26. YEANG, R. T. T. \& TSE, T. F. - Thyrotoxic periodic paralysis: effect of propranolol. Amer. J. Med. 57:584, 1974.

Servigo de Neurologia e Neurocirurgia Dr, Mario Coutinho - Hospital Beneficencia Portuguesa - Avenida Independencia - 90000 Porto Alegre, RS - Brasil. 